\title{
Development and validation of an analytical method using UPLC-MS/MS to quantify everolimus in dried blood spots in the oncology setting
}

Citation for published version (APA):

Knapen, L. M., de Beer, Y., Bruggemann, R. J. M., Stolk, L. M., de Vries, F., Tjan-Heijnen, V. C. G., van Erp, N. P., \& Croes, S. (2018). Development and validation of an analytical method using UPLC-MS/MS to quantify everolimus in dried blood spots in the oncology setting. Journal of Pharmaceutical and Biomedical Analysis, 149, 106-113. https://doi.org/10.1016/j.jpba.2017.10.039

Document status and date:

Published: 05/02/2018

DOI:

10.1016/j.jpba.2017.10.039

Document Version:

Publisher's PDF, also known as Version of record

\section{Document license:}

Taverne

Please check the document version of this publication:

- A submitted manuscript is the version of the article upon submission and before peer-review. There can be important differences between the submitted version and the official published version of record.

People interested in the research are advised to contact the author for the final version of the publication, or visit the DOI to the publisher's website.

- The final author version and the galley proof are versions of the publication after peer review.

- The final published version features the final layout of the paper including the volume, issue and page numbers.

Link to publication

\footnotetext{
General rights rights.

- You may freely distribute the URL identifying the publication in the public portal. please follow below link for the End User Agreement:

www.umlib.nl/taverne-license

Take down policy

If you believe that this document breaches copyright please contact us at:

repository@maastrichtuniversity.nl

providing details and we will investigate your claim.
}

Copyright and moral rights for the publications made accessible in the public portal are retained by the authors and/or other copyright owners and it is a condition of accessing publications that users recognise and abide by the legal requirements associated with these

- Users may download and print one copy of any publication from the public portal for the purpose of private study or research.

- You may not further distribute the material or use it for any profit-making activity or commercial gain

If the publication is distributed under the terms of Article 25fa of the Dutch Copyright Act, indicated by the "Taverne" license above, 


\title{
Development and validation of an analytical method using UPLC-MS/MS to quantify everolimus in dried blood spots in the oncology setting
}

\author{
Lotte M. Knapen a,b, Yvo de Beer ${ }^{a}$, Roger J.M. Brüggemann ${ }^{c}$, Leo M. Stolk ${ }^{\mathrm{a}, \mathrm{b}}$, \\ Frank de Vries $^{\mathrm{a}, \mathrm{b}, \mathrm{d}, \mathrm{e}}$, Vivianne C.G. Tjan-Heijnen ${ }^{\mathrm{f}, \mathrm{g}}$, Nielka P.van Erp ${ }^{\mathrm{c}}$, Sander Croes ${ }^{\mathrm{a}, \mathrm{b}, *}$ \\ a Department of Clinical Pharmacy and Toxicology, Maastricht University Medical Center+, P.O. BOX 5800, 6202 AZ, Maastricht, The Netherlands \\ ${ }^{\mathrm{b}}$ CAPHRI-Care And Primary Health Research Institute, Maastricht University Medical Center+, P.O. BOX 616, 6200 MD, Maastricht, The Netherlands \\ ' Department of Pharmacy, Radboud University Medical Center, P.O. BOX 9101, 6500 HB, Nijmegen, The Netherlands \\ d Department of Pharmacoepidemiology and Clinical Pharmacology, Utrecht Institute for Pharmaceutical Sciences, P.O. BOX 80082, 3508 TB, Utrecht, The \\ Netherlands \\ ${ }^{\mathrm{e}}$ MRC Lifecourse Epidemiology Unit, Southampton General Hospital, University of Southampton, SO16 6YD, UK \\ f Department of Medical Oncology, Maastricht University Medical Center+, P.O. BOX 5800, 6202 AZ, Maastricht, The Netherlands \\ ${ }^{g}$ GROW-School for Oncology and Developmental Biology, Maastricht University Medical Center+, P.O. BOX 616, 6200 MD, Maastricht, The Netherlands
}

\section{A R T I C L E I N F O}

\section{Article history:}

Received 29 June 2017

Received in revised form 26 October 2017

Accepted 28 October 2017

Available online 29 October 2017

\section{Keywords:}

Everolimus

Dried blood spot testing

Analytical method

Oncology

UPLC-MS/MS

Hematocrit

\begin{abstract}
A B S T R A C T
While the therapeutic drug monitoring (TDM) of everolimus has been routinely performed for over 10 years in solid organ transplantation medicine, in order to optimize the balance between effectiveness and toxicity, it is yet uncommon in the treatment of malignancies. The aim of this study was to develop and validate a bioanalytical method to quantify everolimus in dried blood spots (DBS) to facilitate TDM for the oncology outpatient setting. The hematocrit effect of everolimus was investigated. An $7.5 \mathrm{~mm}$ disk from the central part of the DBS was punched, followed by the extraction of everolimus from the DBS by methanol/acetonitrile (80/20\%) spiked with deuterium-labelled everolimus as internal standard. Subsequently, everolimus was separated and analyzed using ultra performance liquid chromatographytandem mass spectrometry (UPLC-MS/MS). The UPLC-MS/MS method was validated according to the European Medicine Agency (EMA) guideline. Everolimus concentrations could be quantified over the range of 3-75 $\mu \mathrm{g} / \mathrm{L}$. The intra- and inter-assay precision and accuracy of the method were shown to be acceptable (coefficient of variation $\leq 10.7 \%$ and relative error $\leq 4.4 \%$, respectively). The matrix effects appeared to be influenced by the hematocrit effect. The hematocrit effect was tested in a range of $0.20-0.50 \mathrm{~L} / \mathrm{L}$, at which hematocrit accuracy and precision were satisfactory at values $\geq 0.25 \mathrm{~L} / \mathrm{L}$. However, at $0.20 \mathrm{~L} / \mathrm{L}$ hematocrit in combination with high everolimus concentrations of 20 and $40 \mu \mathrm{g} / \mathrm{L}$, the precision was adequate $(\leq 7.4 \%)$, but the accuracy was $>15 \%$ of the nominal concentration. Everolimus was stable in DBS for at least 80 days at $2-8{ }^{\circ} \mathrm{C}$. Given these results, the everolimus DBS method has been successfully developed and validated. Special attention is necessary for cancer patients with both a $0.20 \mathrm{~L} / \mathrm{L}$ hematocrit in combination with everolimus concentrations $\geq 20 \mu \mathrm{g} / \mathrm{L}$. A clinical validation for the use of everolimus DBS in cancer patients is currently being undertaken.
\end{abstract}

(c) 2017 Elsevier B.V. All rights reserved.

\section{Introduction}

Everolimus is an oral mammalian target of rapamycin (mTOR) inhibitor that inhibits the oncogenic PI3K/AKT/mTOR driver

\footnotetext{
* Corresponding author at: Maastricht University Medical Center(MUMC+), Maastricht, Department of Clinical Pharmacy and Toxicology, CAPHRI - Care and Primary Health Research Institute, P.O. BOX 5800, 6202 AZ Maastricht, The Netherlands.

E-mail address: s.croes@mumc.nl (S. Croes).
}

pathway and is approved for the treatment of metastatic (hormonereceptor positive, HER2-negative) breast cancer, advanced or unresectable neuroendocrine tumors of pancreatic, gastrointestinal or lung origin and metastatic renal cell carcinoma [1]. Despite the proven efficacy, serious adverse events (i.e. NCI-CTCAE grade 3 or higher) occur frequently, being hyperglycaemia (up to $12 \%$ ), stomatitis (up to $9 \%$ ), anemia (up to $9 \%$ ), and diarrhoea (up to $6 \%$ ) [2-5]. Their management consists of dose reductions, treatment 
cycle interruptions or even complete discontinuation of everolimus [2-5].

Currently, everolimus is used at a fixed oral dose of $10 \mathrm{mg}$ once daily, which may be reduced in case of toxicity or fragility [1]. However, it seems important to guide everolimus dosing pharmacokinetically, since everolimus is well known for its large interpatient pharmacokinetic variability, dose proportional pharmacokinetics, relatively small therapeutic window and exposure-response relationship [6-11]. The therapeutic window of area under the concentration-time curve or trough everolimus concentrations is not established yet, although it is assumed to be $\pm 12-26 \mu \mathrm{g} / \mathrm{L}[8-11]$.

Therapeutic drug monitoring (TDM) is the measurement of drug concentrations in blood to determine pharmacokinetic parameters, in order to optimize individual dosage regimes. Dried blood spot (DBS) sampling by finger prick for the use of TDM has become more common over the years, including the oncology field [12-18]. DBS sampling is minimally invasive and is a promising patient-friendly alternative to venous sampling, since this technique can be performed by patients at their homes and the samples can be sent to the laboratory by regular mail for analysis $[12,13]$. The physician may benefit from the ease of the DBS sampling method, since analysis results are available before the patient visits the clinic for their (routine) check-up [12,13]. Moreover, it is possible that DBS will be used in the future to determine all routine check-up parameters, enabling the patient to visit the hospital less frequently.

TDM of everolimus, including DBS, is routinely performed in solid organ transplantation medicine for over 10 years to balance between effectiveness and toxicity [7,12]. Therefore, a number of DBS everolimus assays have already been developed and validated $[12,13,19,20]$. However, these assays cannot easily be extrapolated to the oncology setting, since the upper range of the calibration curves is relatively low (up to a maximum of $50 \mu \mathrm{g} / \mathrm{L}$ ) and the hematocrit effect is often not or only poorly investigated $[12,13,19,20]$.

It is important to investigate the influence of the hematocrit effect, since it is known that hematocrit varies widely in patients with cancer and that hematocrit can significantly affect analytical results $[8,13,21,22]$. Lower hematocrit values may impact the disposition of everolimus due to chromatographical effects, causing a higher concentration at the periphery of the DBS as compared to the concentration at the center $[19,23]$. Moreover, the DBS area may increase at lower hematocrit values due to the reduced blood viscosity and higher permeability through the DBS paper [19]. However, it is important to note that the hematocrit effect is not the only variable influencing the analytical results [24].

Therefore, the objective of this study was to develop and analytically validate a DBS sampling method for everolimus in the oncology outpatient setting using ultra performance liquid chromatography-tandem mass spectrometry (UPLC-MS/MS). Special attention was paid to the effect of varying hematocrit levels on quantification of everolimus.

\section{Experimental}

\subsection{Chemicals and reagents}

Everolimus standard vial of $1000 \mathrm{mg} / \mathrm{L}$ in acetonitrile was purchased from Cerilliant Corporation (Round Rock, Texas, USA). As internal standard (IS), deuterium-labelled everolimus (everolimus-D4) was purchased from Toronto Research Chemicals (TRC) (Toronto, Ontario, Canada). Methanol and formic acid of LC/MS grade were obtained from Biosolve (Valkenswaard, the Netherlands), ammonium acetate and ethanol absolute PA grade were obtained from Merck (Darmstadt, Germany). Ultrapure water was supplied with a Millipore Milli-Q water purification system from Merck-Millipore (Darmstadt, Germany).

A lyophilised certified external quality control of $5.04 \mu \mathrm{g} / \mathrm{L}$ based on human whole-blood (range 3.53-6.56 $\mu \mathrm{g} / \mathrm{L}$ ) from Chromsystems (Gräffelfing, Germany) was used. The sampling paper used was Protein saver 903, ref no. 10531018, and was obtained from Whatman Gmbh (Dassel, Germany). Costar spin-X high performance liquid chromatography (HPLC) $0.2 \mu$ m nylon filter, catalogue no. 8169 , was used as the micro-centrifuge filter. Everolimusfree blood was collected from healthy volunteers in spray-coated $\mathrm{K}_{2}$ EDTA tubes. Plasma was purchased from Sanquin (Amsterdam, the Netherlands).

\subsection{Preparation of stock and extraction solutions}

Separate batches of everolimus stock solutions for calibrators and quality control samples were prepared in ethanol $(100 \mathrm{mg} / \mathrm{L})$. The IS stock solution was prepared by dissolving $1 \mathrm{mg}$ of everolimus-D4 in $100.0 \mathrm{~mL}$ methanol $(10 \mathrm{mg} / \mathrm{L})$. Both the everolimus and IS stock solution were stored at $2-8^{\circ} \mathrm{C}$. Under these conditions, all solutions are expected to be stable for at least 90 days $[12,25]$.

The extraction solution containing IS was prepared by adding $75 \mu \mathrm{L}$ of the IS stock solution $(10 \mathrm{mg} / \mathrm{L})$ to methanol in $25.0 \mathrm{~mL}$. Subsequently, $1.0 \mathrm{~mL}$ of this solution was added to a methanol/acetonitrile (80/20\%) solution resulting in a total $10.0 \mathrm{~mL}$ volume.

\subsection{Preparation of calibrators and quality control samples}

The everolimus stock solutions for quality controls and calibrators $(100 \mathrm{mg} / \mathrm{L})$ were diluted with millipore water to a concentration of $5 \mathrm{mg} / \mathrm{L}$. These solutions were added to fresh everolimus-free EDTA blood in order to obtain 500 and $50 \mu \mathrm{g} / \mathrm{L}$ working solutions of everolimus in the blood. These solutions were further diluted with fresh everolimus-free EDTA blood to obtain the calibration standards and quality controls (QC). The calibration standards were prepared at the following concentrations 3, 5, 10, 20, 30 and $50 \mu \mathrm{g} / \mathrm{L}$. Additionally, a blank and a zero sample was incorporated in the analysis. In addition, five levels of $\mathrm{QC}$ were prepared: Lower Limit Of Quantification (LLOQ) $3 \mu \mathrm{g} / \mathrm{L}$, Low-Level (QCL) $6 \mu \mathrm{g} / \mathrm{L}$, Mid-Level (QCM) $25 \mu \mathrm{g} / \mathrm{L}$, High-Level (QCH) $40 \mu \mathrm{g} / \mathrm{L}$ and Upper Limit of Quantification (ULOQ) $75 \mu \mathrm{g} / \mathrm{L}$. The LLOQ was set at $3 \mu \mathrm{g} / \mathrm{L}$ which was sufficient for the purpose of the assay in the oncology setting, and adequate sensitivity with minimal signal to noise peak area ratio of 5 could be achieved. The prepared whole-blood standards were tested by our validated venous immunosuppressants method (including everolimus), using the certified external QC from Chromsystems, as part of quality assurance before proceeding to sample preparation of DBS according to Section 2.4.

\subsection{DBS sample preparation and extraction}

DBS sample preparation and extraction procedure were conducted largely according to methods that have been described previously [12]. In short, the DBS samples were prepared by sampling $30 \mu \mathrm{L}$ of blood with a positive displacement pipette onto sampling paper. The DBS were kept overnight to dry at room temperature and then stored at $2-8{ }^{\circ} \mathrm{C}$ in a sealed plastic bag.

For analysis a $7.5 \mathrm{~mm}$ disk from the central part of the DBS was punched out with an electromagnetic driven hole puncher [12]. The disk was placed into a Costar spin-x HPLC micro centrifuge $0.2 \mu \mathrm{m}$ filter, pressed onto the filter [12], after which $200 \mu \mathrm{L}$ extraction solution was added. The samples were sonicated for $30 \mathrm{~min}$, centrifuged at $3506 \times g$ for 5 min and the filter was discarded from the 
Costar tube. The extracts were vortexed for $5 \mathrm{~s}$ after which they were transferred in a $300 \mu \mathrm{L}$ autosampler polypropylene vial. $6 \mu \mathrm{L}$ was injected onto the UPLC-MS/MS system.

\subsection{UPLC chromatography and mass-spectrometry}

Liquid chromatography was performed using a Waters UPLC Hclass system (Waters, Milford, Massachusetts, USA). The sample was injected directly onto an analytical column (Waters Acquity UPLC BEH C18 $1.7 \mu \mathrm{m}$ column, $2.1 \mathrm{~mm} \times 50 \mathrm{~mm}$ ), which was heated to $60^{\circ} \mathrm{C}$. Chromatographic separation was performed by gradient analysis with a flow of $0.5 \mathrm{~mL} / \mathrm{min}$ and a run time of $2.5 \mathrm{~min}$. Mobile phase A consisted of a mixture of $0.1 \%$ formic acid and $2 \mathrm{mmol}$ of ammonium acetate in water, mobile phase B consisted of $0.1 \%$ formic acid and $2 \mathrm{mmol}$ of ammonium acetate in methanol. The following linear gradient was used at the flow rate of $0.5 \mathrm{~mL} / \mathrm{min}$ : time scale (min-min) mobile phase A (\%)/mobile phase B (\%): 0-0.5 35/65 $\rightarrow 0.5-2.00 / 100 \rightarrow 2.0-3.5$ 35/65 (reconditioning of the column). The UPLC system was directly coupled to the mass-spectrometer and the autosampler temperature was held at $10^{\circ} \mathrm{C}$.

Determination of everolimus and the internal standard (everolimus-D4) was performed on a Xevo TQ-S micro Triple Quadrupole mass-spectrometer fitted with an electrospray ionization (ESI) source operating in the positive ion mode (Waters, Manchester, UK). The following internal parameters of the device were used: reaction monitoring of $\left(\mathrm{M}+\mathrm{NH}_{4}\right)^{+}$[precursor/product] $\mathrm{m} / \mathrm{z}$ transitions everolimus (975.8/908.5) and IS (979.8/912.5), source temperature $150^{\circ} \mathrm{C}$, electrospray capillary voltage $1.0 \mathrm{kV}$, sample cone voltage $50 \mathrm{~V}$, collision energy $16 \mathrm{~V}$, desolvation temperature $400{ }^{\circ} \mathrm{C}$ and dwell time $20 \mathrm{~ms}$ for everolimus and $10 \mathrm{~ms}$ for everolimus-D4. The cone gas (nitrogen) flow was set to $50 \mathrm{~L} / \mathrm{Hr}$, the desolvation gas (nitrogen) flow to $1000 \mathrm{~L} / \mathrm{Hr}$, and the collision gas used was argon. The retention time was approximately $1.0 \mathrm{~min}$. System control and data acquisition were performed with MassLynx software (version 4.1, Waters, Etten-Leur, the Netherlands).

\subsection{Method validation}

The analytical method validation was performed at a standardized $0.40 \mathrm{~L} / \mathrm{L}$ hematocrit value and included selectivity, linearity, precision, accuracy, matrix effects, recovery, carry-over and stability according to international European Medicine Agency (EMA) guideline [26]. It is important to note that currently no regulatorybased DBS validation guideline exists, although it is generally accepted that the validation parameters should include hematocrit effect and blood spot size [27]. Therefore, our analytical validation was extended with the investigation of the influence of these parameters on the precision and accuracy.

Accuracy and precision were calculated by the analysis of the QC DBS samples LLOQ, QCL, QCM, QCH and ULOQ. Each QC DBS sample was freshly prepared in fivefold, processed and measured in three separate analytical runs on 3 different days. The intra-, inter-day and overall precision were calculated. To be specific, overall precision was calculated as the coefficient of variation $(\mathrm{CV})$ based on all 15 measurements over the 3 days. All calculations were performed using Microsoft Office Excel (Version 2010, Microsoft Inc, Radmond, WA).

To investigate selectivity, DBS samples were made from six everolimus-free volunteers. The selectivity was investigated to assess whether endogenous compounds from DBS could interfere with the detection of everolimus and the IS.

Linearity was investigated by analyzing in DBS non-zero wholeblood calibrators in duplicate on three different days. The ratio of everolimus peak area to that of IS area at each concentration was plotted as a function of the everolimus concentration, and were fit- ted with $1 / x$ weighted linear regression. The linearity was evaluated by means of back-calculated concentrations of the calibrators.

The matrix effect was assessed by spiking six different blank matrices with 5 and $40 \mu \mathrm{g} /$ Leverolimus (concentrations close to the QCL and ULOQ, respectively). The DBS were prepared in duplicate according to Section 2.4, after which the samples were measured.

We designed an experiment to assess the recovery, and the influence of the hematocrit and stability on the recovery. Whole-blood was prepared at most prevalent hematocrit values of the intended oncology patient population (i.e. $0.35,0.40$ and $0.45 \mathrm{~L} / \mathrm{L}$ ), and spiked with 5 and $40 \mu \mathrm{g} / \mathrm{L}$ everolimus. Subsequently, $15 \mu \mathrm{L}$ of the wholeblood samples were analyzed in duplicate. For the recovery, DBS were prepared in duplicate according to Section 2.4 yet using a blood spotting volume of $15 \mu \mathrm{L}$. The DBS samples were respectively directly analyzed, and analyzed after being stored for 17 days at 2-8 ${ }^{\circ} \mathrm{C}$.

Carry-over effects were investigated in fivefold by injecting a blank sample after injecting the ULOQ sample (i.e. $75 \mathrm{ug} / \mathrm{L}$ ).

Stability of the DBS samples was investigated during transport conditions in addition to storage at $2-8^{\circ} \mathrm{C}$ or $15-25^{\circ} \mathrm{C}$ pending batch-wise analysis. In order to investigate transport conditions, we performed stability testing after 10 and 17 days, at the temperatures -20 to $-30^{\circ} \mathrm{C}, 2-8{ }^{\circ} \mathrm{C}, 15-25^{\circ} \mathrm{C}$ and $40^{\circ} \mathrm{C}$. In order to investigate the possibility of storing the DBS at $2-8^{\circ} \mathrm{C}$ or $15-25^{\circ} \mathrm{C}$ followed by the batch-wise analysis, we performed stability testing after 10,17, 40 and 80 days. The stability was tested at the 5 and $50 \mu \mathrm{g} / \mathrm{L}$ concentration levels (concentrations close to the QCL and ULOQ, respectively). Moreover, stability was tested over the whole range of the calibration curve to gain insight in the stability over a broad concentration range. Therefore, DBS were prepared in duplicate using whole-blood spiked with 5 and $50 \mathrm{ug} / \mathrm{L}$, in addition to all calibrator concentrations (i.e. 3, 5, 10, 20, 30 and $50 \mathrm{ug} / \mathrm{l}$ ). Autosampler stability was investigated by storing the extracted everolimus samples in the autosampler for $24 \mathrm{~h}$ with the temperature set at $10^{\circ} \mathrm{C}$.

\subsubsection{Influence of hematocrit and concentration on accuracy}

The influence of the hematocrit effect in combination with the everolimus concentration was investigated. DBS were prepared in duplicate using whole-blood prepared at a broad range hematocrit values (i.e. $0.20,0.25,0.30,0.35,0.40$ and $0.50 \mathrm{~L} / \mathrm{L}$ ) and spiked with respectively 5,20 and $40 \mu \mathrm{g} / \mathrm{L}$ everolimus [8,13,21,22]. The hematocrit levels used represent the common hematocrit levels of an oncology patient population $[8,21,22]$.

\subsubsection{Influence of hematocrit and spot volume on difference in slope}

The influence of the blood spotting volumes in combination with the hematocrit effect was assessed. DBS were prepared in duplicate using whole-blood prepared at $0.20 \mathrm{~L} / \mathrm{L}$ and $0.40 \mathrm{~L} / \mathrm{L}$, in combination with varying blood spotting volumes of $20-50 \mu \mathrm{L}$ (in $10 \mu \mathrm{L}$ increments) $[19,23,28]$. The whole-blood was spiked with everolimus concentrations over the whole range of the calibration curve, to gain insight in the hematocrit and blood spotting volume effect over a broad concentration range. The $0.20 \mathrm{~L} / \mathrm{L}$ and $0.40 \mathrm{~L} / \mathrm{L}$ hematocrit levels represent the typically lowest and most prevalent hematocrit levels in the oncology population $[8,21,22]$.

\section{Results and discussion}

\subsection{Validation procedure}

The method fulfilled all acceptance criteria regarding accuracy and precision of the calibrators and QCs. The acceptance criteria regarding the calibrators was a maximum accuracy of $\leq 15 \%$ as compared to the nominal concentration, except for $\leq 20 \%$ for the LLOQ 
Table 1

Accuracy and precision results of the quality controls for everolimus DBS.

\begin{tabular}{|c|c|c|c|c|c|}
\hline $\begin{array}{l}\text { Nominal } \\
\text { concentration } \\
(\mu \mathrm{g} / \mathrm{L})\end{array}$ & $\begin{array}{l}\text { Intra-day accuracy } \\
(\mathrm{n}=5)(\%)\end{array}$ & $\begin{array}{l}\text { Inter-day accuracy } \\
(\mathrm{n}=15)(\%)\end{array}$ & $\begin{array}{l}\text { Intra-day precision }{ }^{\mathrm{a}} \\
(\mathrm{n}=5)(\% \mathrm{CV})\end{array}$ & $\begin{array}{l}\text { Inter-day precision }{ }^{\mathrm{b}} \\
(\mathrm{n}=15)(\% \mathrm{CV})\end{array}$ & $\begin{array}{l}\text { Overall precision } \\
(n=15)(\% C V)\end{array}$ \\
\hline LLOQ (3) & 107.6 & 104.4 & 10.7 & 0.0 & 8.5 \\
\hline QCL (6) & 106.4 & 103.0 & 6.7 & 1.9 & 5.3 \\
\hline QCM (25) & 95.6 & 100.6 & 9.9 & 2.8 & 7.8 \\
\hline $\mathrm{QCH}(40)$ & 103.6 & 100.7 & 3.6 & 0.6 & 5.8 \\
\hline ULOQ (75) & 98.1 & 98.9 & 8.0 & 0.0 & 6.4 \\
\hline
\end{tabular}

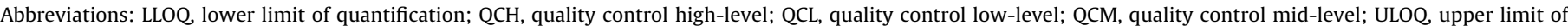
quantification.

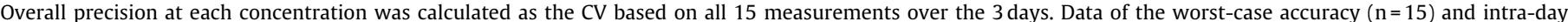
precision $(n=5)$ were reported.

a Others may refer to this as 'within-day precision'.

b Others may refer to this as 'between-day precision'.

\section{(A)}
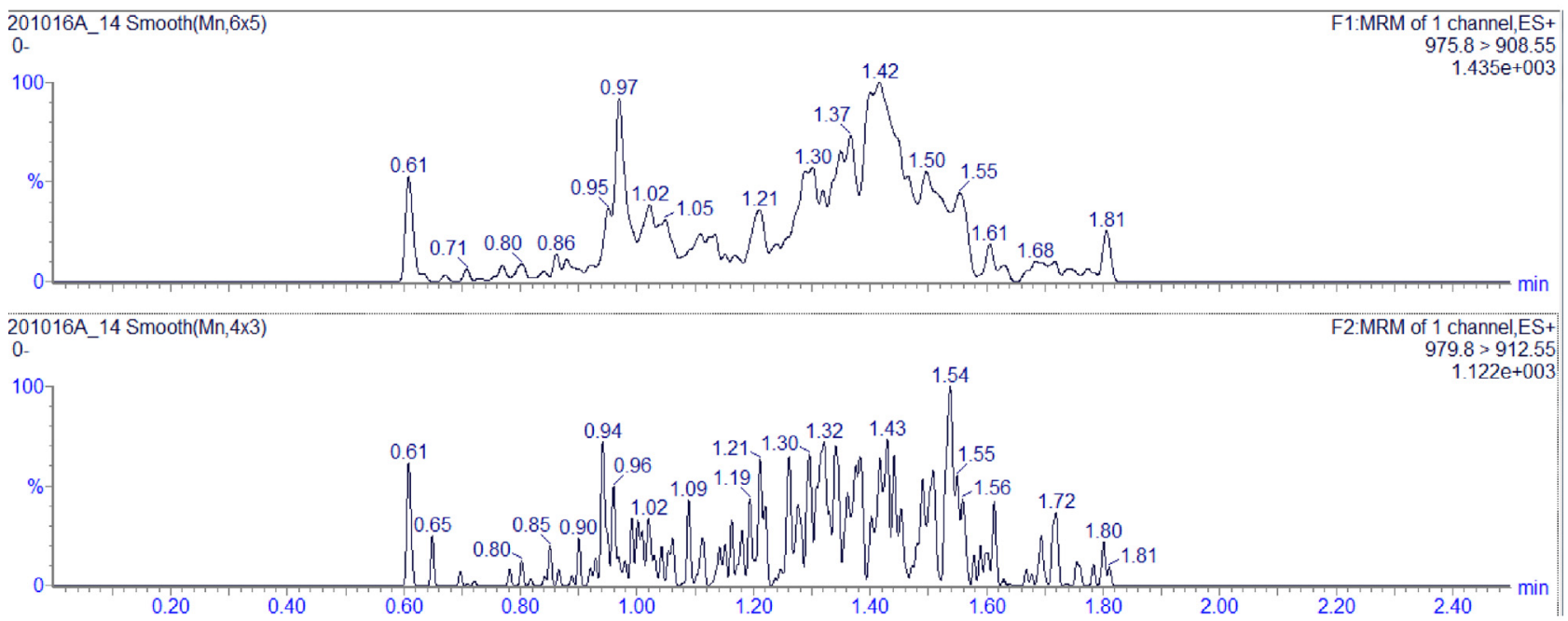

\section{(B)}
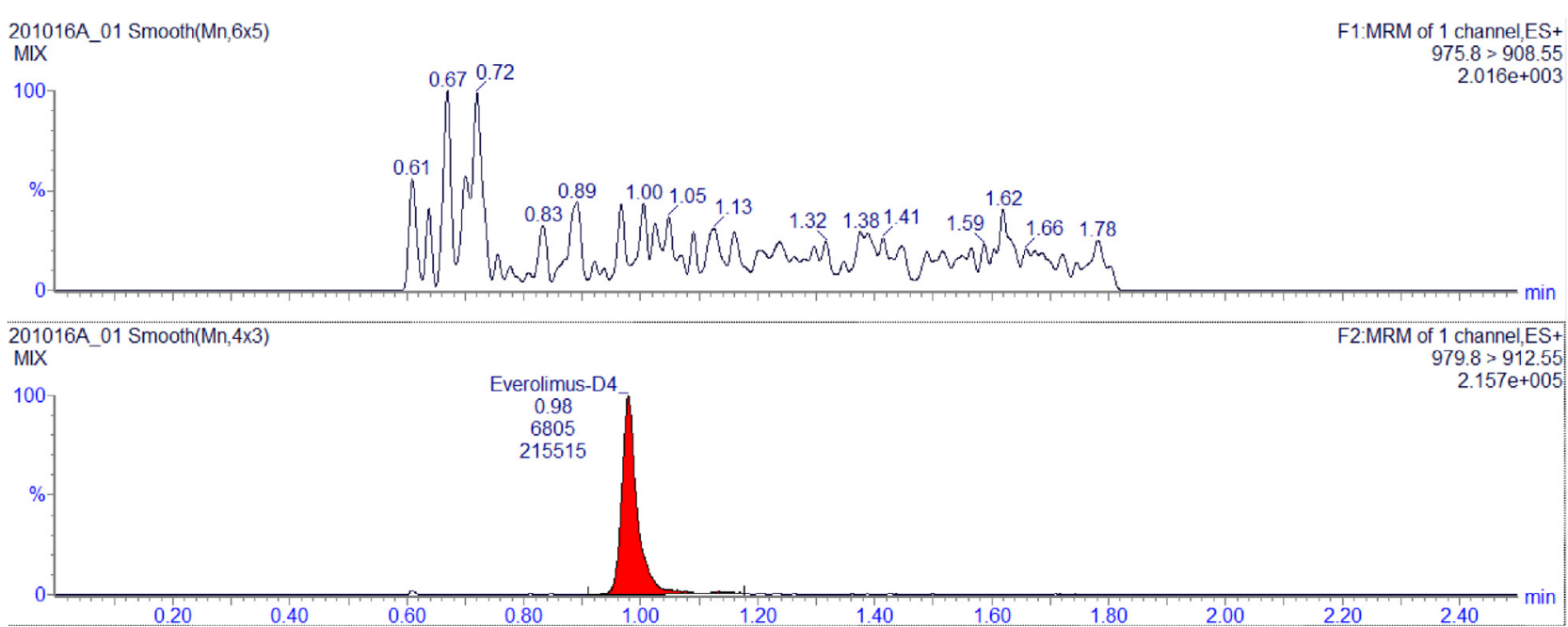

Fig. 1. A chromatogram of a blank (A), and a blank with the addition of the internal standard (B).

and regarding the QCs a maximum intra- and inter-day precision of $\leq 15 \%$ [26]. The deviation of the individual calibration standards was respectively highest at $3 \mu \mathrm{g} / \mathrm{L}(17.1 \%)$ and lowest at $50 \mu \mathrm{g} / \mathrm{L}$
(2.7\%) (results not provided). Table 1 shows the validation results regarding intra- and inter-day accuracy and precision of the QCs. The highest CV value for precision and percentage for accuracy for 
(A)

201016A_09 Smooth(Mn,6x5)

LLOQ-1
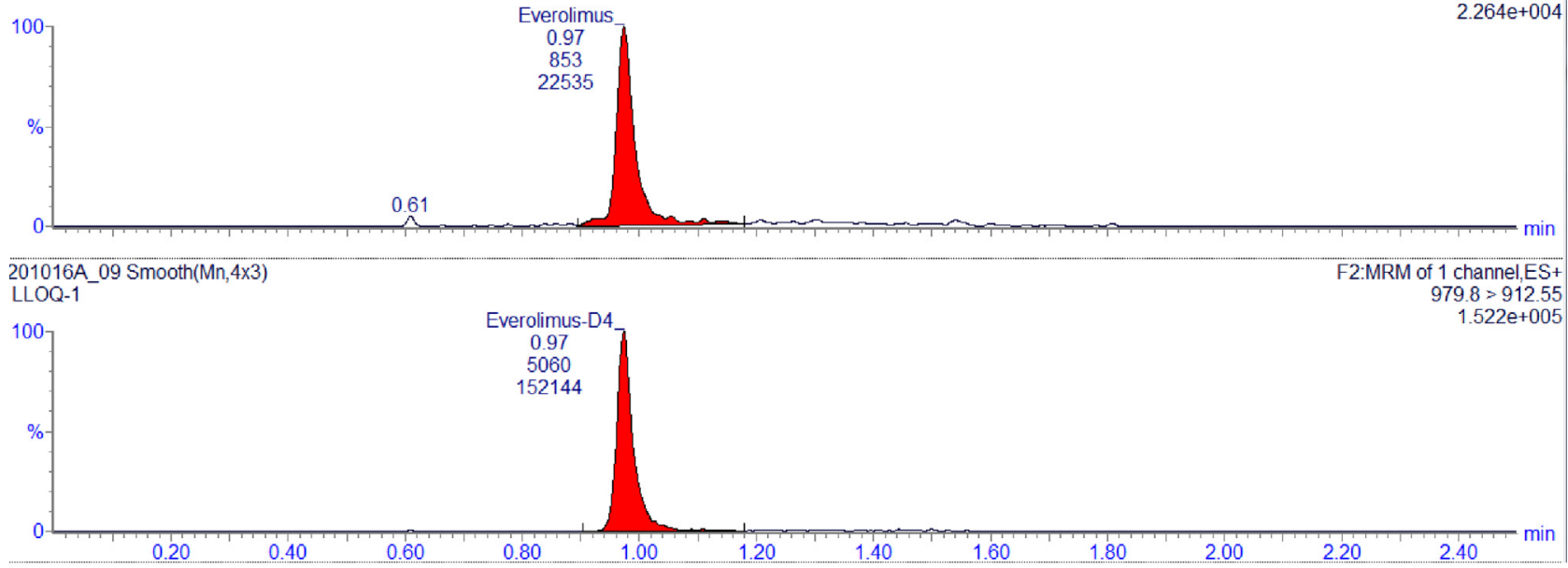

\section{(B)}
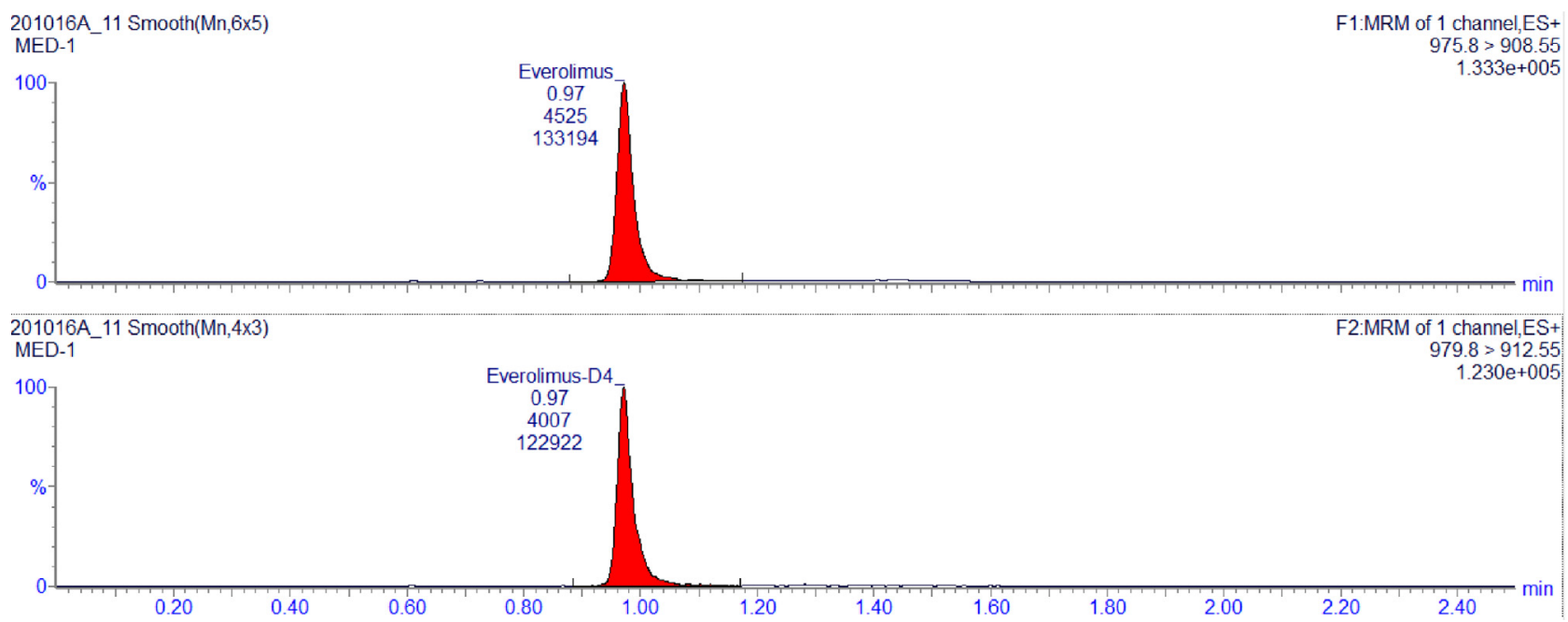

Fig. 2. The typical chromatogram of respectively the LLOQ $(3 \mu \mathrm{g} / \mathrm{L})(\mathrm{A})$ and the $\mathrm{QCM}(25 \mu \mathrm{g} / \mathrm{L})$ (B).

the QCs was respectively $\leq 10.7 \%$ and $\leq 7.6 \%$ of the nominal value [26]. A chromatogram of a blank and a blank with the addition of the IS is shown in Fig. $1 \mathrm{~A}$ and $\mathrm{B}$, respectively, and a chromatogram of the LLOQ and QCM is shown in Fig. 2A and B, respectively. The peak of everolimus at the LLOQ had a signal-to-noise ratio $(\mathrm{S} / \mathrm{N})$ of 13 for everolimus, and 36 for the IS. The limit of detection was set at three times the noise, and was calculated to be $0.6 \mu \mathrm{g} / \mathrm{L}$.

Selectivity was sufficient as no interfering endogenous compounds eluting close to everolimus and IS were observed. All the responses of the six everolimus-free volunteer DBS samples were $<20 \%$ for the LLOQ and $<5 \%$ for the IS, which fell well within the acceptable limit [26].

Everolimus was validated with a linear range of $3-75 \mu \mathrm{g} / \mathrm{L}$. The method showed a good performance in terms of linearity $\left(r^{2} \geq 0.994\right)$, as described by the following three analytical run equations: $y=0.0470 x+0.0053\left(r^{2}=0.996\right), y=0.0460 x+0.0054$ $\left(r^{2}=0.999\right)$, and $y=0.0465 x+0.0056\left(r^{2}=0.994\right)$, where y represents the peak area ratio of everolimus to that of IS and $x$ is the concentration of everolimus in DBS.
The matrix effect did not meet all acceptance criteria, since the precision at $5 \mu \mathrm{g} / \mathrm{L}$ was $15.6 \%$ (Table 2). The acceptance criteria were defined as a maximum precision of the concentration and a maximum precision of the response ratio of $\leq 15 \%$ [26]. The large precision at $5 \mu \mathrm{g} / \mathrm{L}$ was likely due to a combination of the following factors: 1) large variability inherent to a DBS method, 2) large variability inherent to the the low everolimus concentration, and 3 ) the hematocrit effect. The hematocrit value of the six everolimus-free volunteer samples was verified, being $0.40,0.40,0.39,0.41,0.30$, and $0.24 \mathrm{~L} / \mathrm{L}$. After excluding the patient with a hematocrit value of $0.24 \mathrm{~L} / \mathrm{L}$, the precision at $5 \mu \mathrm{g} / \mathrm{L}$ was $14.8 \%$. Furthermore, the precision of all response ratios were $<15 \%$ (with or without excluding the patient with a hematocrit value of $0.24 \mathrm{~L} / \mathrm{L}$ ). Therefore, we expect the matrix effect to be adequate.

The mean recovery was $74 \%$ for the freshly prepared DBS samples and $81 \%$ for the DBS samples stored for 17 days at $2-8{ }^{\circ} \mathrm{C}$ (Table 3). The recovery was not influenced by the hematocrit effect (i.e $0.35 \mathrm{~L} / \mathrm{L}, 0.40 \mathrm{~L} / \mathrm{L}$ and $0.45 \mathrm{~L} / \mathrm{L}$ ). The precision at $5 \mu \mathrm{g} / \mathrm{L}$ and $0.35 \mathrm{~L} / \mathrm{L}$ for the freshly prepared DBS was $15.5 \%$, which was likely 


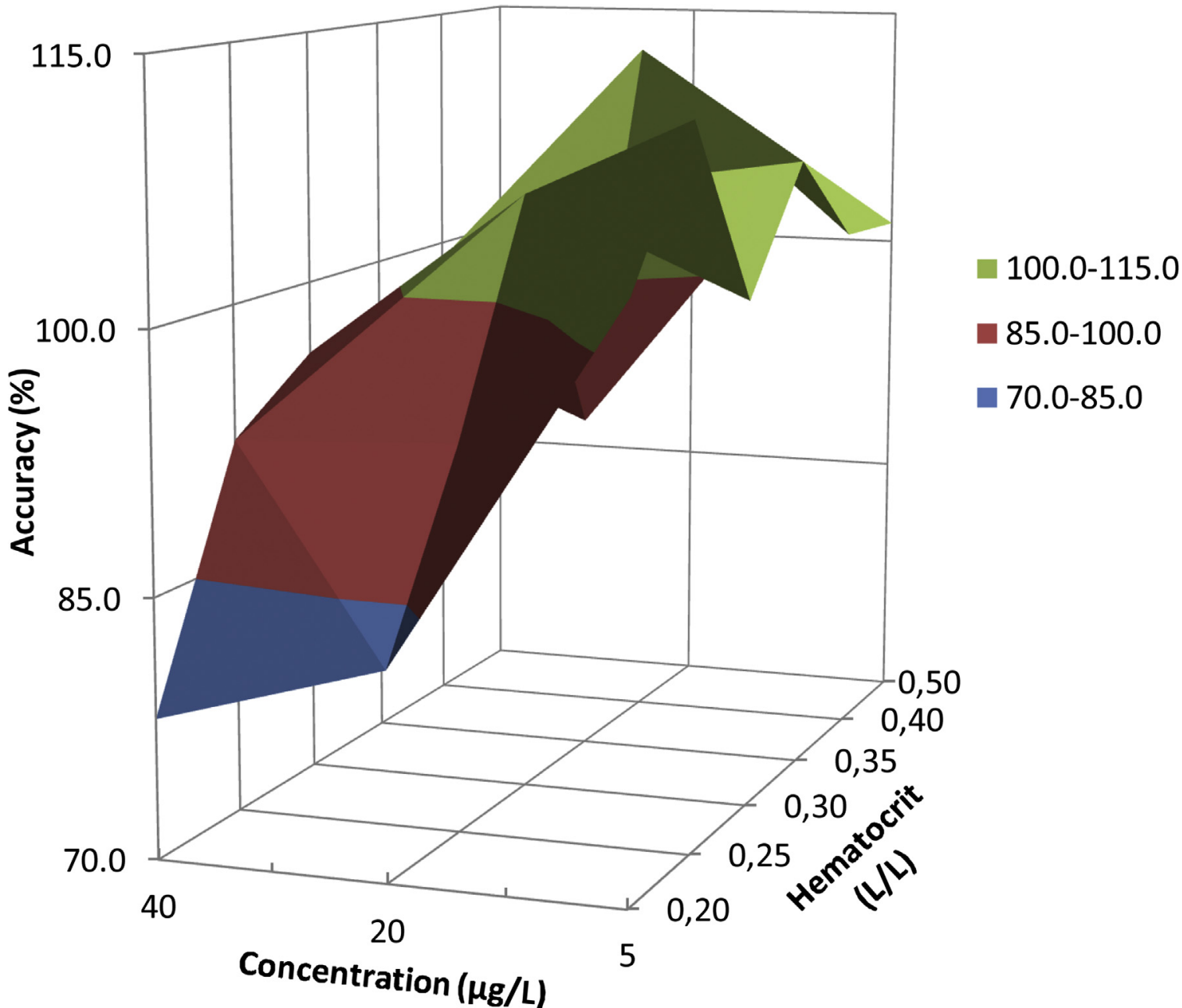

Fig. 3. The accuracy for everolimus DBS influenced by hematocrit and concentration.

Table 2

Matrix effect for everolimus DBS.

\begin{tabular}{|c|c|c|c|c|c|c|}
\hline $\begin{array}{l}\text { Nominal concentration } \\
(\mu \mathrm{g} / \mathrm{L})\end{array}$ & $\begin{array}{l}\text { Mean concentration } \\
(\mathrm{n}=6)(\mu \mathrm{g} / \mathrm{L})\end{array}$ & $\begin{array}{l}\text { Precision }(\mathrm{n}=6) \\
(\% \mathrm{CV})\end{array}$ & $\begin{array}{l}\text { Precision of response } \\
\text { ratio }(n=6)(\% C V)\end{array}$ & $\begin{array}{l}\text { Mean } \\
\text { concentration }^{\mathrm{a}}(\mathrm{n}=5) \\
(\mu \mathrm{g} / \mathrm{L})\end{array}$ & $\begin{array}{l}\text { Precision }^{\mathrm{a}}(\mathrm{n}=5) \\
(\% \mathrm{CV})\end{array}$ & $\begin{array}{l}\text { Precision of response } \\
\text { ratio }^{\mathrm{a}}(\mathrm{n}=5)(\% \mathrm{CV})\end{array}$ \\
\hline 5 & 6.0 & 15.6 & 12.4 & 6.0 & 14.8 & 11.7 \\
\hline 40 & 42.6 & 5.8 & 5.5 & 43.1 & 4.7 & 4.5 \\
\hline
\end{tabular}

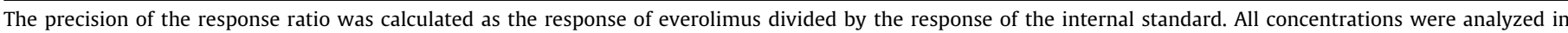
duplicate.

a Patient with hematocrit value of $0.24 \mathrm{~L} / \mathrm{L}$ was excluded.

Table 3

Recovery for everolimus DBS depending on storage, concentration and hematocrit.

\begin{tabular}{|c|c|c|c|c|}
\hline \multirow[t]{2}{*}{ Concentration $(\mu \mathrm{g} / \mathrm{L})$ \& hematocrit $(\mathrm{L} / \mathrm{L})$} & Precision (CV\%) & Recovery (\%) & Precision (CV\%) & Recovery (\%) \\
\hline & \multicolumn{2}{|l|}{ No storage } & \multicolumn{2}{|c|}{ Storage for 17 days at $2-8^{\circ} \mathrm{C}$} \\
\hline $5 \& 0.35$ & 15.5 & 76.6 & 9.2 & 92.1 \\
\hline $5 \& 0.40$ & 3.4 & 80.6 & 3.7 & 70.2 \\
\hline $5 \& 0.45$ & 9.7 & 73.6 & 13.8 & 76.9 \\
\hline $40 \& 0.35$ & 3.2 & 73.8 & 12.2 & 89.9 \\
\hline $40 \& 0.40$ & 5.9 & 69.7 & 8.3 & 80.0 \\
\hline $40 \& 0.45$ & 5.8 & 67.3 & 10.2 & 77.2 \\
\hline
\end{tabular}

All concentrations were analyzed in duplicate.

due to the large variability inherent to the low everolimus concentration in combination with the small amount of blood (i.e. $15 \mu \mathrm{L}$ ).

Carry-over was observed in 5 of the 5 blank samples of the LLOQ and the IS, however, the amount of carry-over fell well within the acceptance criteria. The acceptance criteria for the carry-over in the blank sample following the ULOQ was $\leq 20 \%$ of the LLOQ and $\leq 5 \%$ of the IS [26]. 
Table 4

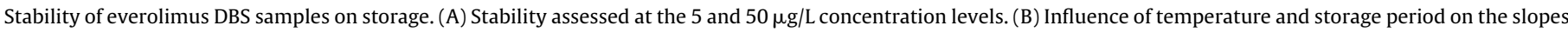
of the everolimus DBS calibration curves.

\begin{tabular}{|c|c|c|c|}
\hline $\begin{array}{l}\text { (A) } \\
\text { Temperature }\left({ }^{\circ} \mathrm{C}\right)\end{array}$ & Time (days) & Accuracy (\%) at $5 \mu \mathrm{g} / \mathrm{L}$ & Accuracy (\%) at $50 \mu \mathrm{g} / \mathrm{L}$ \\
\hline-20 to -30 & 10 & 86.5 & 104.7 \\
\hline-20 to -30 & 17 & 102.5 & 102.8 \\
\hline $2-8$ & 10 & 97.6 & 97.3 \\
\hline $2-8$ & 17 & 86.7 & 106.7 \\
\hline $2-8$ & 40 & 89.0 & 98.2 \\
\hline $2-8$ & 80 & 94.7 & 87.1 \\
\hline $15-25(\mathrm{RT})$ & 10 & 89.4 & 91.3 \\
\hline $15-25(\mathrm{RT})$ & 17 & 94.2 & 98.5 \\
\hline $15-25(\mathrm{RT})$ & 40 & 87.3 & 82.9 \\
\hline $15-25(\mathrm{RT})$ & 80 & 87.3 & 90.9 \\
\hline 40 & 10 & 89.3 & 79.5 \\
\hline 40 & 17 & 88.7 & 92.1 \\
\hline
\end{tabular}

Abbreviation: RT, room temperature.

Table gives mean concentration compared with nominal value. All concentrations were analyzed in duplicate.

(B)

\begin{tabular}{|c|c|c|c|c|}
\hline Temperature $\left({ }^{\circ} \mathrm{C}\right)$ & Time (days) & Intercept & Slope & Difference in slope (\%) \\
\hline-20 to -30 & 10 & -0.0190 & 0.0454 & 101.8 \\
\hline-20 to -30 & 17 & 0.0109 & 0.0434 & 100.4 \\
\hline $2-8$ & 10 & 0.0096 & 0.0428 & 96.0 \\
\hline $2-8$ & 17 & 0.0365 & 0.0440 & 101.8 \\
\hline $2-8$ & 40 & 0.0038 & 0.0410 & 91.7 \\
\hline $2-8$ & 80 & 0.0036 & 0.0358 & 90.5 \\
\hline 15-25 (RT) & 10 & 0.0078 & 0.0399 & 89.4 \\
\hline 15-25 (RT) & 17 & 0.0086 & 0.0421 & 97.2 \\
\hline $15-25$ (RT) & 40 & 0.0174 & 0.0375 & 83.8 \\
\hline $15-25$ (RT) & 80 & 0.0081 & 0.0371 & 94.0 \\
\hline 40 & 10 & 0.0191 & 0.0358 & 80.3 \\
\hline 40 & 17 & 0.0023 & 0.0415 & 96.0 \\
\hline
\end{tabular}

Abbreviations: Ref, reference; RT, room temperature.

Table gives slopes of stored calibration curves compared with the slopes of freshly prepared calibration curves.

The slope of each calibration curve is based on the concentration of 6 calibrators that were analyzed in duplicate.

The stability results are shown in Table $4 \mathrm{~A}$ and B. Everolimus was proven to be stable for at least 80 days when storing at $2-8{ }^{\circ} \mathrm{C}$ and for 17 days at $15-25^{\circ} \mathrm{C}$. Furthermore, the autosampler stability was proven sufficient for $24 \mathrm{~h}$ at $10^{\circ} \mathrm{C}$, since all accuracies were within $\pm 2.7 \%$ (results not provided). The acceptance criteria for the stability were a maximum accuracy for the concentration at 5 and $50 \mu \mathrm{g} / \mathrm{L}$ of $\leq 15 \%$ as compared to the nominal concentration in addition to a maximum allowable difference of the slopes of the calibration curves of the stability samples of $\leq 15 \%$ as compared to the slopes of the freshly prepared calibration curves [26].

\subsubsection{Influence of hematocrit and concentration on accuracy}

Accuracy and precision were satisfactory at all hematocrit levels $\geq 0.25 \mathrm{~L} / \mathrm{L}$, since the precision and accuracy of the hematocrit and concentration samples should be $\leq 15 \%$ (Fig. 3). At $0.20 \mathrm{~L} / \mathrm{L}$ hematocrit in combination with high everolimus concentrations of 20 and $40 \mu \mathrm{g} / \mathrm{L}$, the precision was adequate $(\leq 7.4 \%)$, however the accuracy was respectively $18.0 \%$ and $21.9 \%$ of the nominal value (Fig. 3). The accuracies $>15 \%$ at hematocrit $0.20 \mathrm{~L} / \mathrm{L}$ in combination with the high everolimus concentrations of 20 and $40 \mu \mathrm{g} / \mathrm{L}$ may be explained by both the hematocrit effect and the relatively high number of hydrogen $(\mathrm{H})$-bond acceptors of everolimus (i.e. 14). At high everolimus concentrations, the cellulose bound fraction on the DBS paper might increase, which might result in lower recoveries [24].

\subsubsection{Influence of hematocrit and spot volume on difference in slope}

At $0.40 \mathrm{~L} / \mathrm{L}$ hematocrit, the blood spot volume showed to be of minor impact on the measured concentrations, illustrated by differences of $\leq 3.5 \%$ for all slopes (Table 5 ). At $0.20 \mathrm{~L} / \mathrm{L}$ hematocrit, the differences of the slopes of the $20 \mu \mathrm{L}, 30 \mu \mathrm{L}, 40 \mu \mathrm{L}$ and $50 \mu \mathrm{L}$ cal- ibration curves were $14.6 \%, 21.7 \%, 14.3 \%$ and $16.4 \%$, respectively. The large differences of the slopes at $0.20 \mathrm{~L} / \mathrm{L}$ hematocrit can likely be explained by the hematocrit effect. Blood with a lower viscosity spreads further on the DBS sampling paper, causing large differences of the slopes since fixed DBS punching areas were measured $[19,23]$. The maximum allowable difference of the slopes of the calibration curves at $0.20 \mathrm{~L} / \mathrm{L}$ and $0.40 \mathrm{~L} / \mathrm{L}$ hematocrit sampled with volumes of $20-50 \mu \mathrm{L}$ should be $\leq 15 \%$ as compared to the slope of the calibration curve at $0.40 \mathrm{~L} / \mathrm{L}$ hematocrit sampled with a volume of $30 \mu \mathrm{L}$.

\section{Conclusion}

The everolimus DBS sampling method has been successfully analytically validated for whole-blood over a range of 3-75 $\mu \mathrm{g} / \mathrm{L}$. As compared to previous published everolimus DBS methods, the total analysis time of this method is short ( 3.5 min versus 6.5 and $4.2 \mathrm{~min}$, respectively) [12,19], and the method does not require an impregnation step [12]. The hematocrit accuracy and precision were satisfactory at hematocrit values $\geq 0.25 \mathrm{~L} / \mathrm{L}$, however, not satisfactory at $0.20 \mathrm{~L} / \mathrm{L}$ hematocrit at the high everolimus concentrations of 20 and $40 \mu \mathrm{g} / \mathrm{L}$. Correction for the hematocrit effect at $0.20 \mathrm{~L} / \mathrm{L}$ can be achieved by preparing a full set of calibration standards at $0.20 \mathrm{~L} / \mathrm{L}$ when the hematocrit value of the samples is expected or measured to be close to $0.20 \mathrm{~L} / \mathrm{L}$ [28]. An alternative method could be analysis of the whole blood spot (instead of center punch), or by using volumetric absorptive microsampling, since these methods analyze a fixed volume of blood $[29,30]$. The validated everolimus assay is currently used in a clinical pharmacokinetic study for the use of everolimus DBS in cancer patients. 
Table 5

Influence of hematocrit and blood spotting volume on the slopes of the everolimus DBS calibration curves.

\begin{tabular}{|c|c|c|c|c|}
\hline Hematocrit (L/L) & Blood spot volume $(\mu \mathrm{L})$ & Intercept & Slope & Difference in slope (\%) \\
\hline 0.20 & 20 & 0.0371 & 0.0287 & 85.4 \\
\hline 0.20 & 30 & 0.0439 & 0.0263 & 78.3 \\
\hline 0.20 & 40 & 0.0293 & 0.0288 & 85.7 \\
\hline 0.20 & 50 & 0.0342 & 0.0281 & 83.6 \\
\hline 0.40 & 20 & 0.0369 & 0.0341 & 101.4 \\
\hline 0.40 & 30 & 0.0535 & 0.0336 & Ref. \\
\hline 0.40 & 40 & 0.0670 & 0.0324 & 96.5 \\
\hline 0.40 & 50 & 0.0686 & 0.0337 & 100.2 \\
\hline
\end{tabular}

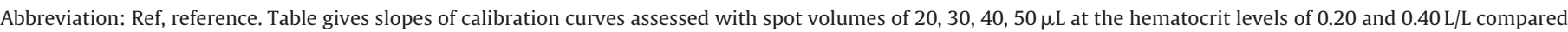

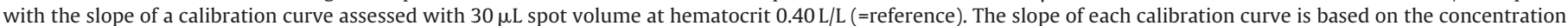
of 6 calibrators that were analyzed in duplicate.

\section{Funding}

This assay development ran parallel with the development of a DBS assay for immunosuppressive agents sponsored in the PROTECT project funded by the Dutch Government, Rational Pharmacotherapy Program, grant 836021012 from the Netherlands Organisation for Health Research and Development (ZONMW).

\section{Conflicts of interest}

None.

\section{Acknowledgements}

None to declare.

\section{References}

[1] EMA, Afinitor-EPAR Product Information, 02, 2009, http://www.ema.europa. eu/docs/en_GB/document_library/EPAR_-_Product_Information/human/ 001038/WC500022814.pdf Accessed 25 February 2017.

[2] J.C. Yao, N. Fazio, S. Singh, et al., Everolimus for the treatment of advanced, non-functional neuroendocrine tumours of the lung or gastrointestinal tract (RADIANT-4): a randomised, placebo-controlled, phase 3 study, Lancet 387 (10022) (2016) 968-977.

[3] J.C. Yao, M.H. Shah, T. Ito, et al., Everolimus for advanced pancreatic neuroendocrine tumors, N. Engl. J. Med. 364 (6) (2011) 514-523.

[4] R.J. Motzer, B. Escudier, S. Oudard, et al., Efficacy of everolimus in advanced renal cell carcinoma: a double-blind, randomized, placebo-controlled phase III trial, Lancet 372 (9637) (2008) 449-456.

[5] J. Baselga, M. Campone, M. Piccart, et al., Everolimus in postmenopausal hormone-receptor-positive advanced breast cancer, N. Engl. J. Med. 366 (6) (2012) 520-529.

[6] US FDA, Afinitor-clinical Pharmacology and Biopharmaceutics Review(s), 2008, http://www.accessdata.fda.gov/drugsatfda_docs/nda/2009/ 022334s000_ClinPharmR.pdf Accessed 2 March 2017.

[7] M. Shipkova, D.A. Hesslink, D.W. Holt, et al., Therapeutic drug monitoring of everolimus: a consensus report, Ther. Drug Monit. 38 (2) (2016) 143-169.

[8] D. de Wit, T.C. Schneider, D.J. Moes, et al., Everolimus pharmacokinetics and its exposure-toxicity relationship in patients with thyroid cancer, Cancer Chemother. Pharmacol. 78 (1) (2016) 63-71.

[9] A. Ravaud, S.R. Urva, K. Grosch, et al., Relationship between everolimus exposure and safety and efficacy: meta-analysis of clinical trials in oncology, Eur. J. Cancer 50 (3) (2014) 486-495.

[10] A. Thiery-Vuillemin, G. Mouillet, T. Nguyen Tan Hon, et al., Impact of everolimus blood concentration on its anti-cancer activity in patients with metastatic renal cell carcinoma, Cancer Chemother. Pharmacol. 73 (5) (2014) 999-1007.

[11] M. Deppenweiler, S. Falkowski, F. Saint-Marcoux, et al., Towards therapeutic drug monitoring of everolimus in cancer? Results of an exploratory study of exposure-effect relationship, Pharmacol. Res. 121 (2017) 138-144.

[12] J. van der Heijden, Y. de Beer, K. Hoogtanders, et al., Therapeutic drug monitoring of everolimus using the dried blood spot method in combination with liquid chromatography-mass spectrometry, J. Pharm. Biomed. Anal. 50 (4) (2009) 664-670.
[13] R.A. Koster, J.W. Alffenaar, B. Greijdanus, et al., Fast LC-MS/MS analysis of tacrolimus, sirolimus, everolimus and cyclosporin A in dried blood spots and the influence of the hematocrit and immunosuppressant concentration on recovery, Talanta 115 (2013) 47-54.

[14] K. Hoogtanders, J. van der Heijden, M. Christiaans, et al., Dried blood spot measurement of tacrolimus is promising for patient monitoring, Transplantation 83 (2) (2007) 237-238.

[15] C.M. Nijenhuis, A.D. Huitema, S. Marchetti, et al., The use of dried blood spots for pharmacokinetic monitoring of vemurafenib treatment in melanoma patients, J. Clin. Pharmacol. 56 (10) (2016) 1307-1312.

[16] D. de Wit, J. den Hartigh, H. Gelderblom, et al., Dried blood spot analysis for therapeutic drug monitoring of pazopanib, J. Clin. Pharmacol. 55 (12) (2015) 1344-1350.

[17] E. Kralj, J. Trontelj, T. Pajič, et al., Simultaneous measurement of imatinib, nilotinib and dasatinib in dried blood spot by ultra high performance liquid chromatography tandem mass spectrometry, J. Chromatogr. B Anal. Technol. Biomed. Life Sci. 903 (2012) 150-156.

[18] N.G. Jager, H. Rosing, J.H. Schellens, et al., Use of dried blood spots for the determination of serum concentrations of tamoxifen and endoxifen, Breast Cancer Res. Treat. 146 (1) (2014) 137-144.

[19] J.C. den Burger, A.J. Wilhelm, A. Chahbouni, et al., Analysis of cyclosporin A, tacrolimus, sirolimus, and everolimus in dried blood spot samples using liquid chromatography tandem mass spectrometry, Anal. Bioanal. Chem. 404 (2012) 1803-1811.

[20] R.A. Koster, H. Veenhof, R. Botma, et al., Dried blood spot validation of five immunosuppressants, without hematocrit correction, on two LC-MS/MS systems, Bioanalysis 9 (7) (2017) 553-563.

[21] N.P. van Erp, C.M. van Herpen, D. de Wit, et al., A semi-physiological population model to quantify the effect of hematocrit on everolimus pharmacokinetics and pharmacodynamics in cancer patients, Clin. Pharmacokinet. 55 (11) (2016) 1447-1456.

[22] K. Knight, S. Wade, L. Balducci, Prevalence and outcomes of anemia in cancer: a systematic review of the literature, Am. J. Med. 5 (2004), 116 Suppl. 7A:11S-26S.

[23] M. Wagner, D. Tonoli, E. Varesio, et al., The use of mass spectrometry to analyze dried blood spots, Mass Spectrom. Rev. 35 (3) (2016) 361-438.

[24] R.A. Koster, J.W. Alffenaar, R. Botma, et al., The relation of the number of hydrogen-bond acceptors with recoveries of immunosuppressants in DBS analysis, Bioanalysis 7 (14) (2015) 1717-1722.

[25] D. Capone, A. Gentile, G. Polichetti, et al., Stability of sirolimus and everolimus measured by immunoassay techniques in whole blood samples from kidney transplant patients, Int. J. Immunopathol. Pharmacol. 21 (2) (2008) 297-307.

[26] EMA, Guideline on Bioanalytical Method Validation, 21, 2011, http://www. ema.europa.eu/docs/en_GB/document_library/Scientific_guideline/2011/08/ WC500109686.pdf Accessed 2 March 2017.

[27] N.G. Jager, H. Rosing, J.H. Schellens, et al., Procedures and practices for the validation of bioanalytical methods using dried blood spots: a review, Bioanalysis 6 (18) (2014) 2481-2514.

[28] A.J. Wilhelm, J.C. den Burger, E.L. Swart, Therapeutic drug monitoring by dried blood spot: progress to date and future directions, Clin. Pharmacokinet. 53 (11) (2014) 961-973.

[29] A.E. Kip, K.C. Kiers, H. Rosing, et al., Volumetric absorptive microsampling (VAMS) as an alternative to conventional dried blood spots in the quantification of miltefosine in dried blood samples, J. Pharm. Biomed. Anal. 135 (2017) 160-166.

[30] N. Zheng, L. Yuan, Q.C. Ji, et al., Center punch and whole spot bioanalysis of apixaban in human dried blood spot samples by UHPLC-MS/MS, J. Chromatogr. B Anal. Technol. Biomed. Life Sci. 988 (2015) 66-74. 